\title{
Derecho del Consumo
}

Francisca Barrientos Camus

Profesora de Derecho Civil

Universidad Diego Portales

Investigadora Fundación Fernando Fueyo

MAPFRE Compañía de Seguros Generales de Chile S.A. CON Nuevos Desarrollos S.A. (2015): Corte de Apelaciones de San Miguel, 18 de MaRZO DE 2015 (ACCIÓN INFRACCIONAL Y ACCIÓN CIVIL), ROL: 1750-2014, CITA WESTLAW CL/JUR/1479/2015; 89567.

¿UNA COMPAÑÍA DE SEGUROS PUEDE SUBROGAR AL CONSUMIDOR?

\section{DESCRIPCIÓN DE LOS HeChOS}

En MAPFRE Compañía de Seguros Generales con Nuevos Desarrollos S.A. se describe que la compañía aseguradora denunció y demandó a la Sociedad Nuevos Desarrollos S.A. ante el Segundo Juzgado de Policía Local de San Bernardo.

El tribunal acogió las peticiones formuladas y condenó a la empresa proveedora a pagar una multa de 20 UTM y la suma de $\$ 2.790 .985$ por concepto de daño emergente, más reajustes e intereses y con condena en costas por haber sido totalmente vencida.

La parte vencida apeló solicitando que se revoque la sentencia apelada o que se rebaje prudencialmente la multa impuesta junto con la indemnización, y que no se le condene en costas por haber tenido motivo plausible para litigar.
En la apelación se sostuvo que el Juzgado de Policía Local sería incompetente para conocer de la causa ${ }^{1}$, ya que la querellante y demandante no detentaba la calidad de consumidora. Además, no se acreditó que el asegurado tenía la calidad consumidor, ni tampoco se probó el robo del vehículo, o que fuera la dueña del automóvil sustraído del mall.

Por su parte, la Corte de Apelaciones de San Miguel confirmó la sentencia apelada tanto en el aspecto infraccional como en el aspecto civil indemnizatorio por el daño emergente.

Y como se anunciaba desde el título de este comentario parece interesante examinar si la calidad de consumidor admite subrogación o no; y de ser así bajo qué condiciones o en qué términos operaría esta institución en este ámbito especial de protección.

A continuación, explicaré de forma breve la regulación del pago con subrogación establecido en el art. 1608 y siguientes del Código Civil y lo dispuesto en el art. 553 del Código de

${ }^{1}$ En esta parte he seguido de cerca la descripción que efectúa la sentencia de la Corte de Apelaciones de San Miguel. Por eso llama la atención que se ventilara el argumento de la competencia en razón de la materia en sede de apelación. 
Comercio; y luego la relación de la voz legal 'consumidor' consagrada en el art. $1 \mathrm{~N}^{\mathrm{O}} 1$ de la LPDC.

\section{EL PAGO CON SUBROGACIÓN}

En general, la subrogación supone:

"la sustitución de una persona o cosa por otra persona o cosa, en términos tales que la nueva pase a ocupar la misma situación jurídica de la anterior" ${ }^{2}$.

Cuando se subroga la calidad de persona a persona, la nueva pasa a ocupar el lugar de la antigua. Por eso, se ha la designado también como un "subingreso" o "subentrada" de un nuevo acreedor en el lugar del antiguo ${ }^{3}$.

$\mathrm{El}$ art. 1608 del $C C$ define subrogación como:

"la transmisión de los derechos del acreedor a un tercero que le paga".

La vinculación entre esta figura y el pago obedece a razones históricas que no se analizarán en este comentario. Por esta razón solo se examinará la regulación que contiene el art. 1608 y siguientes del $C C$, que lo consideran como una ficción que no extingue la obligación.

En realidad, esta institución operaría como una cesión de derechos de carácter ficticia como lo señala, con acierto, Luis Claro Solar ${ }^{4}$ o, tal vez, como

${ }^{2}$ Crf. Abeliuk (2014), p. 793.

${ }^{3}$ Díez Picazo (2008), p. 991.

${ }^{4}$ Así, por ejemplo, lo explica Luis Claro Solar en los siguientes términos: "La subrogación una modalidad de pago en virtud de la cual se produce la cesión de derechos. Se trata de una regla de equity que se suele justificar como una cesión de derechos.

De este modo, en las reglas civiles no se distingue quién paga, pero sí el grado o nivel de interés que presenta el pagador. Así, se subrogarían estos sujetos en los derechos del acreedor para obtener la restitución de lo debido, sea porque se comprometieron o porque se vieron forzados a hacerlo.

Gracias a la subrogación legal ${ }^{5}$, que opera aun por el ministerio de la ley y aun contra la voluntad del acreedor, nacería lo que se ha denominado un "pacto tácito a favor del deudor" en virtud del cual se le "transmiten" al sujeto que pagó los derechos del acreedor. Y desde ahora en adelante él se transformará en el nuevo acreedor.

Como lo señalaba Luis Claro So$\operatorname{lar}^{8}$ la subrogación concilia todos los intereses; los del acreedor, porque recibe lo debido, y también los de los

es, por lo mismo, una ficción que impide el efecto natural del pago hecho al acreedor se realice; pues la subrogación se opera con respecto al crédito mismo que el tercero paga al acreedor y como consecuencia de ello respecto de las garantías personales y reales del mismo crédito. Esta ficción, establecida en interés del subrogado, consiste en que se reputa que ha comprado más bien que pagado el crédito: la subrogación se presenta así como una cesión de derechos ficticia", Claro Solar (2013), p. 200 y él mismo (2013), No 1512, p. 202.

${ }^{5}$ Esta es la que interesa para efectos de este comentario.

${ }^{6}$ Díez Picazo (2008), p. 995.

${ }^{7}$ Expresión que ha sido criticada por su conexión con la sucesión por causa de muerte, cfr. Claro Solar (2013), p. 201; Abeliuk (2014), p. 786.

${ }^{8}$ Claro Solar (2013), p. 194. 
codeudores no interesados porque ayudan o colaboran con el deudor. Aunque hay que reconocer, como lo hace Luis Díez Picazo ${ }^{9}$, que se trataría, más bien, de una institución favor creditoris toda vez que intenta privilegiar al solvens que pagó el crédito de su acreedor.

Y en sintonía con lo que se analiza, esta subrogación sería de corte personal o subjetiva, ya que:

“...traspasa al nuevo acreedor todos los derechos, acciones, privilegios, prendas e hipotecas del antiguo, así contra el deudor principal, como contra cualesquiera terceros obligados solidaria o subsidiariamente a la deuda" (art. 1612 del CC).

De este modo, esta clase de subrogación traspasará al acreedor todo o parte del crédito subrogado con todas las prescripciones que contiene la norma citada.

Para efectos de este comentario resulta interesante examinar si se traspasan todos los privilegios del acreedor o solo los inherentes al crédito transmisibles, tema que está relacionado con el traspaso de la calidad o posición jurídica de "acreedor".

Sobre este punto, Luis Claro Solar consideraba que los privilegios personales se traspasarían porque el art. 1612 del $C C$, que trata los efectos de la subrogación, no hacen ninguna distinción. No ha establecido que solo los privilegios inherentes al crédito lo hagan, de manera que:

\footnotetext{
${ }^{9}$ Díez Picazo (2008), p. 1002.
}

"La ley no establece esta limitación; y establecerla importa dictar una ley, que el legislador no ha establecido" ${ }^{10}$.

Arturo Alessandri ${ }^{11}$, que a propósito de un comentario de sentencia criticaba una resolución judicial que no reconoció que las hipotecas pasan al subrogado por el solo ministerio de la ley sin que sea necesario anotarlas en el Conservador, ha expresado que sería contrario a la postura antes señalada; y en un intento de extender su argumento, dice que reconocería solo los traspasos inherentes al crédito.

René Abeliuk ${ }^{12}$ propone una distinción. En su concepto habrían ciertos privilegios que serían inherentes al crédito, tal como ocurre con los intereses o los mismos privilegios personales que son susceptibles de ser traspasados en virtud de la subrogación; mientras que existirían otros como la suspensión de la prescripción o la competencia por el fuero personal que no podrían subrogarse.

En lo personal no creo que se transmita la calidad personal o subjetiva de "acreedor", sino que los derechos que tiene ese sujeto en el crédito con todos sus accesorios y privilegios. Por eso, se trata de un "pago con subrogación" y no una subrogación propiamente $\operatorname{tal}^{13}$.

${ }^{10}$ Claro Solar (2013), p. 247. Junto con ello, funda su argumento en la disposición del art. 2470 del $C C$ que hala sobre los "privilegios", en op. cit., p. 248. Pero esa misma disposición establece que son inherentes al crédito.

${ }^{11}$ Alessandri Rodríguez (1924).

12 Abeliuk (2014), p. 810.

${ }^{13}$ De todas formas surge la duda con los privilegios personalísimos del acreedor, pero si se 
Ayuda en esta interpretación lo dispuesto en los arts. 1906 y 2470 del $C C$ que hacen referencia a las limitaciones de la cesión de créditos y al concepto de privilegios desde la perspectiva del crédito y no de la persona y sus cualidades personalisímas. Misma regla que por analogía podría deducirse a propósito de la situación del heredero, pues como se ha sostenido su calidad es indeleble ${ }^{14}$; o con la misma orientación respecto del rechazo de lege lata de la interposición de la acción de reclamación de filiación en contra de los herederos del supuesto padre fallecido ${ }^{15}$.

En suma, bajo las reglas civiles el pago por subrogación importaría el traspaso de todos los derechos, acciones, privilegios, prendas e hipotecas inherentes al crédito, sin considerar los privilegios subjetivos inherentes a la persona.

Para continuar hay que señalar que como en este caso se alegó la subrogación de las reglas del Código de Comercio que operan a favor de la compañía aseguradora, conviene ahora mostrar una breve parte de sus reglas.

En materia de seguros, la compañía de seguros cuenta con una disposición especial que le autoriza a subrogarse en los derechos del asegurado para recuperar parte del siniestro pagado ${ }^{16}$.

toma en consideración que son inherentes a los créditos, aun cuando hayan sido establecidos a favor de una persona, tal como lo parece reflejar el art. 1906 del $C C$, el problema se desdibuja. 22 .

${ }^{14}$ Domínguez y Domínguez (1984), pp. $17-$

${ }^{15}$ Corral Talciani (2009), pp. 7-22.

${ }^{16}$ Para profundizar sobre este tema y en general sobre las reglas de seguro con una visión comparada, véase DíAz y NASSER (2015), p. 491 y ss.

Así, en el CCom se regula una nueva clase de subrogación. En efecto, el art. 534 dispone:

"Por el pago de la indemnización, el asegurador se subroga en los derechos y acciones que el asegurado tenga en contra de terceros en razón del siniestro".

Si se analiza esta figura es posible observar que se asimilaría a una subrogación de aquellas que se conocen como personales ${ }^{17}$, pues la compañía aseguradora asume los derechos o créditos de la persona del asegurado cuando paga la indemnización que surge en razón del siniestro.

Entonces, a falta de una regulación especial, por integración, se infiere que la compañía aseguradora traspasaría el crédito subrogado con todos sus derechos, acciones, privilegios y eventuales prendas o hipotecas que posea el asegurado. Y con ello el subrogado estaría en condiciones de solicitar el pago de lo debido al acreedor.

Y en esta materia se puede presentar la misma discusión que se suscita en sede civil a propósito de qué es lo que se subroga: si los privilegios personales del asegurado (y con ello su posición o calidad) o el crédito y privilegios inherentes a él.

Para avanzar, relacionaré esta materia con la idea de que el asegurado puede ser considerado como consumi-

${ }^{17}$ Aun cuando no me convence la distinción, he decidido sistematizarla siguiendo las directrices tradicionales del tratamiento nacional de la subrogación y el pago con subrogación. 
dor. Por ello, a continuación se analizará su definición legal en la LPDC.

\section{LA CALIDAD DE CONSUMIDOR}

El cliente de una compañía de seguros puede ser considerado como consumidor para los efectos de la LPDC.

$\mathrm{Y}$ en realidad, al menos desde la praxis judicial, hoy resulta difícil encontrar fallos (de los detectados en los portales de recopilación de sentencias) que rechacen la calidad de consumidor del asegurado.

La LPDC define al consumidor como el destinatario final. Se trata de las

"personas naturales o jurídicas que, en virtud de cualquier acto jurídico oneroso, adquieren, utilizan, o disfrutan, como destinatarios finales, bienes o servicios" (art. $1 \mathrm{~N}^{\circ} 1$ de la LPDC).

En otras ocasiones se ha criticado la exigencia del acto jurídico onero$\mathrm{so}^{18}$, pues condicionaría la protección legal sólo hacia los contratantes. Por eso, se defiende que el énfasis debería estar puesto en la destinación final. Tal como se desprende del análisis de las sentencias actuales de los jueces de Policía Local y cortes de Apelaciones

${ }^{18}$ Barrientos (2011a), pp. 55-80; BARRIENTOS (2011b), pp. 363-285. Y sin pretender ahondar en esta materia tan solo diré que la destinación final supone que la persona consumidora será el último sujeto de la cadena de consumo. Así las cosas, el consumidor o usuario de lege lata sería el destinatario final de los bienes y servicios de elaboración masiva, con independencia del título que justifica la adquisición. De lege ferenda se recomienda suprimir la exigencia del acto jurídico oneroso. que han centrado su mirada en este requisito prescindiendo de los demás.

En teoría, las definiciones de consumidor pueden ser subbjetivas u objetivas ${ }^{19}$. La noción subjetiva pone el acento en la persona misma del consumidor, mientras que las expresiones objetivas se centran en el acto de consumo, más allá de la persona.

Me parece que la definición nacional de consumidor sería subjetiva, porque solo se requiere cumplir con la destinación final, incluso cuando abarca a un gran número de personas indeterminadas (v.gr. las tutelas supraindividuales difusas). Para estos efectos, no importaría que el sea acto mixto (civil para él y mercantil para el proveedor) o como se ha expuesto, si es oneroso o no.

Por esta razón sería cuestionable que una persona que no cumpla con la destinación final de los bienes o servicios sea considerada como consumidora, aun por algún tipo de cesión ${ }^{20}$, pues se le atribuiría a su favor una serie de mecanismos de protección mediante técnicas de derechos irrenunciables pensados en un contexto de mercado de manufacturación masiva que disciplina las relaciones entre los clientes (consumidores) y los empresarios.

De esta manera la "calidad de consumidor" podría ser considerada como una vinculación especial subjetiva, tal como ocurre con la "calidad de heredero" que, como he expuesto con anterioridad, se ha calificado como indeleble. Lo anterior no niega la subroga-

${ }^{19}$ Un estudio sobre las nociones de consumidor puede consultarse en Botana (1990), pp. 54-72.

${ }^{20}$ Sin tomar en consideración la sucesión por causa de muerte. 
ción de los derechos, créditos y acciones que se radican en su patrimonio.

Inclusive, desde otra perspectiva se han justificado diversos mecanismos de "traspaso" intervivos para evitar que los cesionarios de los consumidores queden en la indefensión. Así, por citar un ejemplo, se planteó en el Derecho español que mediante el traspaso de la boleta se cedería la garantía legal a través de un título portable ejercitable para el que lo tenga en su poder ${ }^{21}$. Algo similar ocurriría en nuestro país con los llamados "tickets de cambio" que, si bien no son mecanismos de tutela de la $\mathrm{LPDC}^{22}$, operan como una especie de título portable innominado.

De ahí que en una primera aproximación al tema, pienso que sería difícil fundamentar la cesión o subrogación de la calidad de consumidor en favor de la compañía aseguradora.

No se duda de la subrogación de las acciones, derechos y, en general, todos los actos de contenido patrimonial que tendría derecho a invocar el sujeto calificado como destinatario final de los bienes o servicios masivos. Por eso, la compañía aseguradora podría solicitar la restitución del valor del automóvil, como en este caso por el valor de $\$ 2.790 .985$ que fue el saldo restante que no obtuvo luego del remate.

Y desde esta perspectiva no podría pedirse en el juicio el reembolso de los gastos no que tienen una naturaleza indemnizatoria susceptible de sobrogación. En este sentido, y con razón a mi juicio, Marcelo Nasser ha comentado:

${ }^{21}$ Álvarez Moreno (2010), pp. 81-128.

${ }^{22}$ En realidad, se tratarían de alternativas voluntarias de los proveedores que intentan fidelizar a sus clientes a través de mejores servicios.
"Se sabe que en la práctica muchas compañías de seguro demandan además del monto indemnizado, los honorarios del liquidador y otros gastos anejos al siniestro. Tales gastos no tienen naturaleza indemnizatoria para el asegurado, y no dan derecho a la subrogación" ${ }^{23}$.

Avanzando un poco más allá, se ha sostenido que la subrogación opera respecto del crédito y también de las acciones procesales que de ellas se derivan, pero surge la interrogante sobre si la compañía aseguradora podría demandar bajo las reglas procesales instituidas a favor del consumidor.

Sin pretender agotar el tema, hay que reconocer que existe una diferencia entre otorgar una acción procesal al subrogante para reclamar lo pagado y otra en tolerar la subrogación de la tutela procesal que el legislador ha considerado para ciertas personas por sus especiales consideraciones.

Y la pregunta parece interesante toda vez que habría que considerar diferencias de competencia, de concentración de procedimiento, de régimen de apreciación de la prueba, de recursos admisibles, entre otros. Más adelante, de prosperar la reforma que pretende el fortalecimiento del Servicio Nacional del Consumidor también cambiarían las reglas sobre el conocimiento de la acción infraccional frente al ente administrativo.

${ }^{23}$ Nasser Olea (2015). La versión comparada con las normas colombianas se encuentra disponible en https://onedrive.live.com/view. aspx?resid=2220067B03E84CA! $112 \&$ ithint $=$ f ile $\% 2$ cpdf\&app $=$ WordPdf\&authkey $=$ !AO6Im p0sGSSTfV0 
En realidad, la cuestión de la subrogación aplicada al ámbito procesal es difícil de resolver.

Quizá, importaría observar la concepción que se tenga sobre la materia y el fuero como factor de competencia y si es que este concepto sería aplicable al tema objeto de este comentario. Aquí conviene recordar que René Abeliuk ${ }^{24}$ lo calificaría como un privilegio personalísimo no susceptible de subrogación. También habría que examinar el régimen de la sustitución procesal o cambio de partes en el proceso ${ }^{25}$ y qué sucede, por ejemplo, cuando se traba la litis.

Para terminar, solo resta volver a señalar que el pagador se subroga en el crédito del consumidor, pero no su calidad. Por ello, el que le paga podrá gozar de todos sus derechos, acciones, privilegios, prendas e hipotecas solo inherentes al crédito.

\section{Biblografía CITADA}

Abeliuk, René (2014). Las obligaciones. $6^{\text {a }}$ ed. actualizada. Santiago: Thomson Reuters Legal Publishing.

Alessandri Rodríguez, Arturo (1924) "Del traspaso del derecho de hipoteca en el pago con subrogación". RDJ, tomo 21, sec. Derecho. Disponible en Legal Publishing cita en línea CL/ DOC/1364/2009.ç

Álvarez Moreno, María Teresa (2010). "La garantía comercial y la figura del productor en la venta de bienes de consumo", en María del Carmen GóMEZ (coord.). Algunos aspectos de las

\footnotetext{
${ }^{24}$ Abeliuk (2014), p. 809.

${ }^{25}$ Romero Seguel (2011), pp. 263-270.
}

garantías de bienes de consumo. Madrid: Editorial Reus.

Barrientos Camus, Francisca (2011a). "Algunas reflexiones sobre el desbordamiento de la responsabilidad infraccional en la Ley $\mathrm{N}^{\circ} 19.496$ ". Revista de Derecho de la Empresa. $\mathrm{N}^{\circ} 25$. Santiago

Barrientos Camus, Francisca (2011b). "El vicio de la cosa comprada. La noción de vicio redhibitorio en el régimen de saneamiento del Código Civil y la Ley sobre protección de los derechos de los consumidores", en Íñigo DE LA Maza (coord.). Cuadernos de Análisis Jurídico: Incumplimiento contractual. Nuevas perspectivas. Santiago: Ediciones Universidad Diego Portales, vol. VII.

Botana García, Gema (1990). "Noción del consumidor en el Derecho comparado". Revista Estudios sobre Consumo. $\mathrm{N}^{\circ}$ 18. Madrid.

Claro Solar, Luis (2013). Explicaciones de derecho civil chileno y comparado. De las obligaciones. Santiago: Editorial Jurídica de Chile. Vol. VI. tomo XII. (reimp. 2013)

Corral Talciani, Hernán (2009). “¿Puede interponerse la acción de reclamación de filiación en contra de los herederos del supuesto padre fallecido?". Gaceta Jurídica. No 347. Santiago. 2009.

DíAz, Ignacio y Marcelo NASser (2015). "Capítulo llamado Chapter 11 (Chile)", in Dennis Campbell (ed.). International Insurance Law and Regulation, Graz: CILS-Thomson-Reuters.

Díez Picazo, Luis (2008). Fundamentos de derecho civil patrimonial II. $6^{\mathrm{a}}$ ed. Pamplona: Thomson Civitas.

Domínguez Benavente, Ramón y Ramón Domínguez Águila (1984). "La 
calidad de heredero es indeleble". Revista de Derecho. No 176. Concepción.

Nasser Olea, Marcelo (2015). "La subrogación del asegurador. Comentario al artículo 534", en Roberto Rios (ed.). Comentarios a la Ley 20.667. Santia go: Legal Publishing-Thomson Reuters (en prensa).

Romero Seguel, Alejandro (2011). "La sucesión procesal o cambio de partes en el proceso civil". Ius et Praxis. Año 17. $\mathrm{N}^{\mathrm{o}} 1$. Talca.

232 